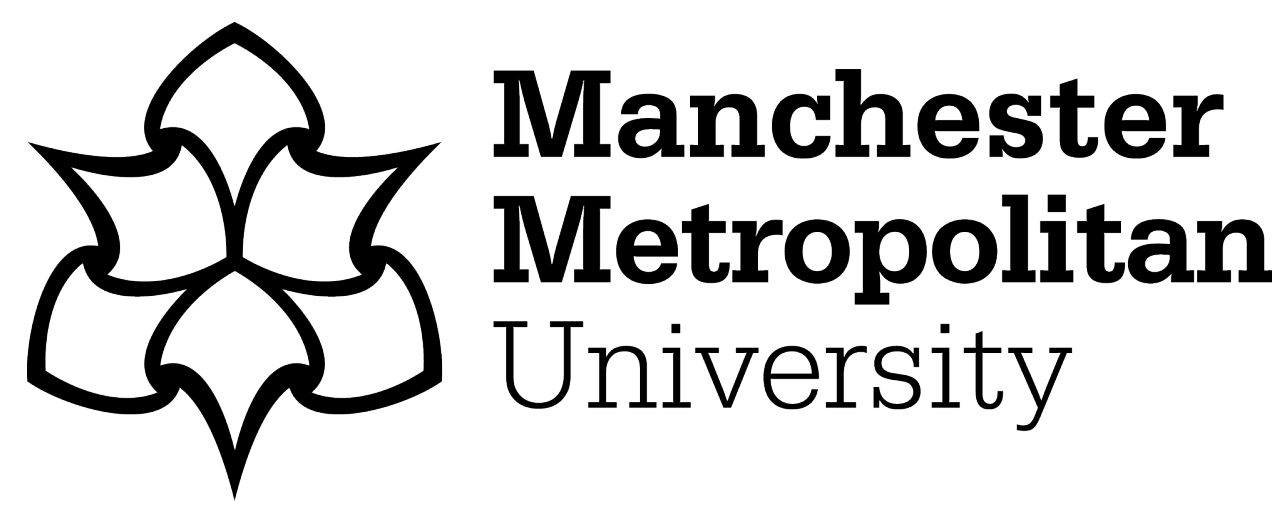

Andriopoulou, Panoraia ORCID logoORCID: https://orcid.org/0000-00025745-6741 and Prowse, Alicia ORCID logoORCID: https://orcid.org/00000002-1425-3274 (2020) 'Towards an effective supervisory relationship in research degree supervision: insights from attachment theory'. Teaching in Higher Education, 25 (5). pp. 648-661. ISSN 1356-2517

Downloaded from: https://e-space.mmu.ac.uk/625495/

Version: Accepted Version

Publisher: Informa UK Limited

DOI: https://doi.org/10.1080/13562517.2020.1731449

Please cite the published version 


\title{
"Towards an effective supervisory relationship in research degree supervision: insights from attachment theory"
}

\author{
Panoraia Andriopoulou ${ }^{\mathrm{a} *}$ and Alicia Prowse ${ }^{\mathrm{b}}$
}

${ }^{a}$ Department of Psychology, Manchester Metropolitan University, Manchester, UK; ${ }^{b}$ University

Teaching Academy, Manchester Metropolitan University, Manchester, UK

Word count: 4611

The authors declare no conflict of interest.

*Requests for reprints should be addressed to Panoraia Andriopoulou, Manchester Metropolitan University, Brooks Building, 53 Bonsall Street, Manchester, M15 6GX, UK (e-mail:

n.andriopoulou@mmu.ac.uk). ORCID ID: 0000-0002-5745-6741 


\begin{abstract}
While the interpersonal nature of the supervisory relationship in research degree supervision has been recognised and different models of supervisory styles have been developed, the research supervision literature has yet to acknowledge the relational individual differences and the relational dynamics that are at play within the supervisor-supervisee relationship. This paper draws on literature from the higher education, clinical supervision, and leadership fields and utilises attachment theory as a conceptual framework in an attempt to shed some light on the attachment process and dynamics of the research supervisory relationship. The review of the evidence presented here clearly indicates the usefulness and applicability of attachment theory in the research supervision practice. This paper makes a contribution to the higher education and research supervision literature by offering new directions for research and by providing practical guidelines for the training of postgraduate research supervisors.
\end{abstract}

Keywords: research supervision, research supervisory relationship, supervisory styles, attachment theory, supervisor training 
"Towards an effective supervisory relationship in research degree supervision: insights from attachment theory"

\section{Introduction}

The low rates of successful doctoral completions and the length of time taken by students to complete their $\mathrm{PhD}$ theses has been a major concern over the last 50 years as a number of reports brought the issue into spotlight with estimates of completion rates varying between $50 \%$ (Wollast et al, 2018) and 83\% (Spronken-Smith, Cameron and Quigg, 2018; Wright and Cochrane, 2000). A number of steps have been taken to ensure the timely submission of doctoral theses. For example, in the United Kingdom, an emphasis on research students' skills development has been based on the Research Development Framework (Vitae, 2011), with close monitoring of their progress employing specialised software systems such as Skillsforge. Introduction of mandatory supervisor training (Bastalich, 2017) and a shift from the funding of PhDs dependent on numbers of enrolments to successful completions have also occurred (McCallin and Nayar, 2012). Research on the factors affecting successful and timely completions has revealed that institutional factors, financial and emotional support, and students' situational factors and intrinsic characteristics influence thesis completion (Lindsay, 2015). Additionally, a special emphasis has been given to the research supervisory relationship with many studies establishing evidence for its paramount importance (e.g., Halbert 2015, Green 2005, Lee 2008) with some scholars urging caution around the risk of supervisors being considered the "distant masters with sole responsibility for 'quality' outcomes" (Bastalich, 2017 p.1146).

Over the last decade, supervision has been conceptualised as professional work (Halse and Malfroy, 2010) and a distinctive form of pedagogy (Guerin et al., 2015; Kamler and Thomson, 2014; McCallin and Nayar, 2012) where supervisors juggle different responsibilities and fulfil 
various roles ranging from project management and teaching research skills to assisting students in dealing with frustrating emotions. However, training for supervisors focuses more on the university policies and procedures and students' skills development (Bastalich, 2017), and less attention is devoted to the relationship itself, overlooking the fact that the research supervisory relationship is above all a human relationship governed by relational and interpersonal processes. A number of pedagogical models (some of them are reviewed in the next section) have been developed with an aim to identify and describe different supervisory styles, along with their strengths and weaknesses, ultimately aiming to match students to supervisors depending on their preferences and research development needs (e.g. Gatfield 2005, Mainhard et al. 2009). However, none of these models has recognised the importance of the supervisors or supervisees dispositional styles of relating (e.g., attachment styles). This is rather surprising given the wealth of compelling evidence coming from the clinical supervision (e.g., Bennett et al. 2008, Watkins and Riggs 2012) and leadership (e.g., Davidovitz et al. 2007, Mayseless and Popper 2019) fields. The research supervisory relationship is above all an interpersonal relationship within which the supervisor does not only meet the student's educational and research needs but also their emotional needs by providing pastoral care and support. Although the supervisor-supervisee relationship cannot be considered as the main source of learning, it is undoubtedly the medium through which effective supervision becomes possible and learning occurs (Roach, Christensen, and Rieger, 2019). Notably, it has been found (Halbert 2015) that students perceive supervision to be of high quality when supervisors are available, approachable, responsive, and supportive. Although other aspects of the supervisory relationship (e.g., expertise in the research process) were identified as important, it was primarily the supervisors' interpersonal characteristics that determined the perception of quality in supervision. As it will become evident in the subsequent 
sections, these characteristics very much resemble (but are not identical) those of a securityproviding attachment-figure.

The present paper aims to summarise the literature of the main supervisory models and to introduce attachment theory as a conceptual framework for doctoral supervision. The main concepts of attachment theory will be presented and empirical evidence of the relevance of attachment theory in the context of supervisor-supervisee and leader-follower relationships will be reviewed. Finally, in the last section the implications for research and practice will be outlined.

\section{Models of Research Degree Supervision and Supervision Pedagogies}

The increased interest in the research supervisory relationship over the last couple of decades has resulted in the development of several pedagogical models of research degree supervision (e.g., Lee 2008, Gurr 2001, Mainhard et al. 2009, Gatfield 2005) which provide useful frameworks but have received little empirical support with regards to their relevance, efficacy and applicability (McCallin and Nayar 2012). For example, there is no research to show whether specific pedagogical models are successful, or more successful than others, in enhancing research students' satisfaction and improving completion rates. In this section, the main supervisory models will be reviewed with a specific emphasis on the relational aspects of the supervisory relationship.

Gurr (2001) in an attempt to develop a model which would be relevant to all disciplines, drew upon Anderson's (1988) ideas of styles of supervision and conceptualised the students' research development as a transition from dependency to competent autonomy. The supervisor needs to alter and align their supervisory approach, ranging from a "hands-on" to "hands-off" style, 
depending on the student's needs and growth trajectory. The Supervisor/Student Alignment model is consequently a bi-dimensional, dynamic model which involves the supervisor and supervisee plotting a representation of their relationship with an aim to enhance self-reflection and to initiate a discussion of the supervisory relationship (Gurr 2001). Although in his 2001 paper Gurr provides some support based on his personal supervisory experiences, the model has received only minimal empirical support (Orellana et al. 2016) and it fails to conceptually acknowledge the inter-relational aspect of the supervisory relationship. Supervisees who have not developed a strong working alliance with their supervisors might find it difficult to openly discuss tension or discord in the supervisory relationship (Nelson et al. 2008).

A slightly later model developed by Gatfield (2005) focused on the supervision processes and the developmental changes that take place over time. Using the Delphi method of review (Boberg and Monis-Khoo 1992), Gatfield and his colleagues reviewed 60 books and journal articles and identified 80 variables which were subsequently clustered into 8 groups. Those clusters were further scaled down to three factors, namely structural, support, and exogenous. The structural factor refers to the institutional processes, the time and project management, the style and format of supervision, and skills provision. The support factor incorporates different aspects of support provided either by the institution (e.g., material, financial, or technical support) or the supervisor (e.g., pastoral support and mentoring). The final factor comprised all those variables that remain relatively stable such as personality characteristics and motives, and interpersonal skills. Gatfield developed his conceptual model incorporating only the first two sets of factors, which were represented in two axes, creating a space of four sections corresponding to four different supervisory styles. More specifically, supervisors who provide low structure and low support adopt a laissez-faire supervisory style, those who provide low structure but high support are 
characterised by a pastoral supervisory style, supervisors with high structure but low support adopt a directorial style, and finally those with high structure and high support prefer a contractual style of supervision. In the original 2005 paper, Gatfield provided some empirical support for his model by interviewing 12 highly skilled supervisors and analysing their data employing the same criteria that were originally used for the development of the model.

In 2008, in an attempt to develop a comprehensive framework of supervision, Lee interviewed 12 supervisors from different disciplines and interpreted their responses in the light of previous literature. The analyses revealed five interdependent approaches of supervision: (a) the functional approach, refers to project and time management; (b) enculturation concerns the supervisor's attempts to facilitate the student's integration into the department, the institute, and the academic community of the discipline in general; (c) critical thinking is related to the supervisee's development of critical faculties; (d) emancipation refers to the conceptualisation of the supervisory relationship as a mentoring or coaching process where the supervisee is encouraged to move from dependence to higher levels of agency and self-development; (e) relationship development pertains to the quality of the supervisory relationship in the context of which the supervisee feels recognised, encouraged, and supported (Lee 2008). Lee's model has been refined and elaborated further (Lee and Murray 2015, Hutchings 2017) and has received some empirical support (Lee, 2018) but there is still no evidence regarding its applicability and its impact on the number of successful completions or students' satisfaction. Supervisors are becoming familiar with the models but not with how to implement them in practice. Nevertheless, Lee's model explicitly incorporates the quality of the supervisory relationship, acknowledging its importance. 
The importance of the interpersonal aspect of the supervisory relationship was also recognised by Mainhard and colleagues (2009) who developed a questionnaire of supervisor-doctoral student interaction (QSDI) to allow the alignment of research students and supervisors based on their personal styles of relating as conceptualised in an interpersonal supervisory model. The model was first developed to analyse teacher behaviour in secondary classrooms (Wubbels et al. 2006) and describes the relationship in bidimensional terms where Influence and Proximity are the two independent dimensions. According to Mainhard and colleagues (2009), the interpersonal style of the supervisor depends on the student with whom they are interacting. Namely, the same supervisor may exhibit completely different behaviours when interacting with different students. According to the model, these behaviours have a degree of Influence and Proximity and are captured in eight types of behaviour: leadership, helpful/friendly, understanding, giving students freedom and responsibility, uncertain, dissatisfied, admonishing and strict (Mainhard et al. 2009). This model bears some similarities with Gatfield's (2005) model described above. However, Mainhard and colleagues' model provide a much more comprehensive depiction of the supervisory relationship as not only does it delineate the interactional nature of the relationship but also allows the mapping of different degrees of behaviour intensity.

Other models focus on attributes of supervisors. For example, Gruzdev, Terentev and Dzhafarova (2019) identified 6 types of supervisors including 'superhero' 'hands off' and 'dialogue partner' from a study of 2034 students at 12 Russian universities. The researchers explored the links between these types of supervisors and students' satisfaction and optimism towards submission, concluding that the 'hands off' supervisory style was associated with lower 
levels of student satisfaction and longer expected submission times than 'superhero' or 'dialogue partner' supervisors.

The very fact that many different models have been developed to depict the supervisory relationship is suggestive of both its importance and complexity (see also Deuchar 2008). A short-coming of the above-mentioned models is that they attempt to conceptualise the relationship as a simple dyadic relationship which is influenced by the demands of the project itself and the institutional processes, but disregard the influence of the not-so-obvious factors such as social position and unequal power, personality and identity, and relational patterns. However, Grant (1999) has recognised the importance of mental representations of past relationships which might be activated during supervisor-supervisee interactions:

"They may remind each other of former significant others (and thus in some sense there are others present in the supervision meeting), or of themselves even. They may feel strong feelings - of gratitude, resentment, frustration, disappointment, love - because of these remindings." (Grant, 1999, p.9).

This idea has not been much pursued in the intervening years and work on the supervisory experience has focused latterly on institutional priorities such as timely completion (e.g. Bowden and Green 2019). An explicit consideration of attachment theory in the context of research student supervision could thus help to illuminate some of the complexities of the studentsupervisor relationship. Consequently, the following sections provide a brief account of attachment theory and its basic concepts and reviews relevant literature from the fields of clinical/counselling supervision and leadership/management. 


\section{Attachment Theory: Basic Concepts}

Attachment theory was introduced by John Bowlby (Bowlby 1988, 1969) a British psychiatrist who was studying the effects of separation from parents early in life. According to his theory, human babies are born with an innate psychobiological system, which allows them to create an emotional bond with a wise and strong significant other to enhance their chances of survival. Bowlby, originally posited that in the context of their interactions with their primary caregivers (or attachment figures), human infants develop mental representations (internal working models; IWM) of themselves and others which act as patterns of relating across the lifespan. When attachment figures are responsive and available in times of need or distress, the infants develop secure IWMs. Conversely, when attachment figures are unresponsive or insensitive to the infants' needs, insecure IWMs emerge. Although these models continue to evolve and elaborate throughout life as individuals interact with new people in their lives, according to attachment theory the IWMs that have been formulated early in life remain highly influential with regards to individuals' social functioning (Collins 1996). Mary Ainsworth, Bowlby's primary collaborator, devised an experimental method, the "Strange Situation" which enabled her to code infants' behaviour when they were separated from their primary caregiver. Based on this laboratory assessment procedure, she classified infants into three attachment types; namely, secure, anxious, and avoidant (the latter two types were originally termed insecure-ambivalent/ resistant and insecure-avoidant respectively) (Ainsworth, Blehar, and Waters 1978). Research on attachment theory has proliferated since then, and attachment is now conceptulised as an orthogonal construct with two dimensions: attachment anxiety and attachment avoidance (Mikulincer and Shaver 2007). Individuals who score high on attachment anxiety hold negative IWMs of themselves and have a fear of abandonment and rejection as they hold beliefs that they 
are not worthy of love and that other will not be consistently responsive to their emotional needs. Those who score high on avoidance, feel uncomfortable with proximity as they hold negative IWMs of others who are considered untrustworthy and unreliable. In contrast, securely-attached persons hold positive IWMs of themselves and others and feel comfortable with closeness and reliance on others as they believe that others will be available in times of need. Importantly, IWMs not only do they influence relational styles and their associate cognitions, but also the person's emotional regulation strategies. Accordingly, anxious individuals tend to hyperactivate the attachment system by being vigilant for signs of others' unavailability or rejection and by intensifying negative emotions whereas avoidant individuals employ deactivating strategies which involve the suppression of emotional experience and compulsive self-reliance. Securelyattached individuals, on the other hand, engage adaptive emotion regulation strategies such as problem solving, cognitive reappraisal, and support seeking (Mikulincer and Shaver 2007, Mikulincer, Shaver, and Pereg 2003).

\section{Attachment Theory and Supervision}

A common misconception about attachment theory is that infants formulate one attachment relationship with their mother which remains influential well into adulthood. Bowlby himself was the first to assume that there is a hierarchy of attachment figures (Bowlby, 1982) as children develop different IWMs for each parent but also for other important people in their lives such as siblings, peers, teachers, members of the extended family etc. It is now widely accepted among attachment scholars that individuals hold multiple attachments with different relationship partners and that the attachment representations of these relationships are organised in a hierarchical manner. Consequently, more general representations (IWMs) of self and others are at the top of the hierarchy, domain-specific representations which refer to specific types of 
relationships (e.g., relationships with parents, siblings, friends, and romantic partners) are further down in the hierarchy, and relationship-specific representations which concern relationships with specific individuals are at the lowest of the hierarchy (Sibley and Overall 2008, Collins 1994, Collins and Read 1994). On the basis of these ideas, and evidence that will be presented below, one can argue that the supervisor-supervisee relationship could be conceptualised as a domainspecific attachment relationship considering that supervisors share similar characteristics with attachment figures, namely they are stronger and wiser significant others who are available and supportive in times of need (Pistole and Watkins 1995). Supervisory relationships were first conceptualised as attachment relationships in the early 1990s (Hill 1992) mainly in the context of clinical supervision and research in the area has grown since then. More recently scholars have suggested that we need to be conscious and conservative when conceptualising the supervisory relationship as "full-blown attachment" since even though this relationship has the potential to develop into an attachment bond over time, this does not necessarily imply that all supervisory relationships bear the characteristics and qualities of an attachment bond (Watkins and Riggs 2012). Nevertheless, there is ample evidence (e.g., Bennett et al. 2008, Rogers et al. 2019, Yip et al. 2018) coming from the fields of clinical supervision and leadership/management which shows that attachment dynamics are activated and attachment processes are enacted in a contextspecific fashion. More specifically, supervisees and followers will turn to their supervisors or leaders for comfort and support when their distress is related to training or performance. Attachment dynamics have also been found to be activated in group contexts (DeMarco and Newheiser, 2019) as individuals can use a group as a secure base from which to explore the world and as a source of support and comfort in times of need (Mikulincer and Shaver, 2007). Individuals who score high on group attachment anxiety or avoidance engage less in group 
activities, evaluate social groups and group interactions more negatively, report lower perceived support from groups, and experience less positive affect during team work (Rom and Mikulincer, 2003; Smith et al., 1999). Marmarosh and Markin (2007) explored the relationship between both group and dyadic attachment styles and college adjustment and found that they both predicted how well students adjusted to college. Most importantly, group attachment predicted college adjustment above and beyond dyadic attachments. This is particularly relevant in research supervisory settings as group supervision is common practice at doctoral level.

\section{Evidence from Leadership and Clinical Supervision Research}

\section{Supervisees'/Followers' attachment style}

Supervisees' general and supervision-specific attachment styles have been found to influence a number of important supervisory outcomes. For example, several studies (Bennett et al. 2008, Renfro-Michel and Sheperis 2009) have shown that supervisees with an insecure attachment style evaluate the supervisory working alliance more negatively in comparison to their secure counterparts. Interestingly, the supervision-specific attachment is a stronger predictor of the perceived quality of the working alliance (Bennett et al. 2008, Wrape et al. 2017). This finding has been confirmed by a more recent study which revealed that individuals who reported anxious or avoidant attachment to their supervisors had poorer perception of the supervisory relationship (McKibben and Webber 2017). Similarly, insecurely attached supervisees not only do they tend to expect a negative supervisory relationship at the beginning of supervision (which indicates that they enter the relationship with negative preconceptions) but also provide poorer evaluations of the supervisory alliance at the end of the semester (Wrape et al. 2017). More recently, the supervisees' attachment organisation has been examined in relation to how receptive they are to corrective feedback and their levels of cognitive distortions (Rogers et al. 2019). Rogers and 
colleagues' findings revealed that both high levels of attachment anxiety and avoidance were significantly correlated with a number of cognitive distortions. In addition, anxious supervisees found it difficult to accept corrective feedback, a finding that is consistent with attachment theory, which posits that anxious individuals hold negative IWMs of themselves, and have fears of being rejected. It is therefore possible that the supervisors' threatening corrective feedback activates the attachment system along with the negative mental representations and emotions rendering it difficult for anxious individuals to accept or utilise feedback. Unsurprisingly, similar evidence comes from the field of leadership where scholars study the dynamics of leaderfollower relationships. For instance, securely attached followers have been found to trust their supervisors and their motives whereas high scores on avoidance have been associated with negative perceptions of benevolence and lower levels of trust in their supervisors (Frazier et al. 2015). In contrast, anxious individuals tend to over-rely on others' feedback as their negative IWMs they hold about themselves cause them to worry too much about their abilities and performance (Wu, Parker, and De Jong 2014).

\section{Supervisors'/Leaders' attachment style}

Evidence for the relevance and applicability of attachment theory in the context of supervisory relationships also comes from research showing that the supervisors' attachment styles are influential in terms of predicting supervisees' ratings of professional development. For example, Foster and colleagues (2006) found that supervisors with an anxious attachment style tend to provide lower ratings for their supervisees' professional development when compared to supervisors with other styles of attachment. The authors claimed that the supervisees' abilities might pose a threat for anxious supervisors' competence and expertise as these supervisors hold negative views (IWMS) of themselves (Foster et al. 2006). In a subsequent study, the same team 
of researchers (Foster, Lichtenberg, and Peyton 2007), recruited supervisor-supervisee dyads from different professional backgrounds to examine the effects of the quality of the supervisory relationship on the supervisees' professional development. The findings indicated that supervisor-specific attachment was significantly correlated to supervisees' general attachment style and that those supervisees who reported a secure attachment relationship with their supervisor rated their overall professional development more positively as compared with insecure supervisees. In a similar vein, (White and Queener 2003) have demonstrated that supervisors' levels of attachment security were predictive of higher ratings of the supervisory alliance as perceived by both supervisors and supervisees. Additionally, it has been shown that supervisees' perceptions of their supervisors attachment style is related to ratings of working alliance. More specifically, supervisees' who perceived their supervisors as secure evaluated the supervisory alliance more positively compared to those who perceived their supervisors as insecurely attached (Riggs and Bretz 2006, Dickson et al. 2011). Leadership research has also produced similar findings (see Yip et al. 2018) for a review). For example, it has been found that insecurely attached leaders and followers tend to evaluate their relationship more negatively (Richards and Hackett 2012). Notably, leaders with an avoidant attachment style are perceived by their followers as unavailable and disapproving which in turns is associated with poorer followers' functioning and mental health (Davidovitz et al. 2007) whereas leaders' high attachment anxiety scores have been found to predict higher levels of negative affect in followers and lower job satisfaction (Kafetsios, Athanasiadou, and Dimou 2014). In addition, anxious leaders seem to have low confidence in their ability to form and maintain successful relations which in turn is associated with abusive supervision (Robertson, Dionisi, and Barling 2018). In contrast, attachment security in leaders has been found to be predictive of charismatic and 
transformational leadership (Popper, Mayseless, and Castelnovo 2000, Mayseless and Popper 2019) and high levels of well-being for followers (Davidovitz et al. 2007, Mayseless and Popper 2019).

\section{Implications for Future Practice and Research}

The evidence presented in the previous section suggest that attachment dynamics and processes are indisputably activated and played out within supervisor-supervisee relationships. It is therefore vital for the universities to include attachment theory explicitly in the training curriculum of supervisors to enhance their understanding of their supervisees' attachment style. The attachment system is activated in times of distress and the doctoral journey can be a very stressful period for candidates. Research has shown that anxiously attached supervisees may lack self-confidence and can be self-critical with regards to their skills and capabilities (McKibben and Webber 2017) and they find it hard to accept and benefit from corrective feedback (Rogers et al. 2019). They might also enter the supervisory relationship with negative expectations, which tend to become more and more pessimistic over time (Watkins and Riggs 2012), as their IWMs lead them to believe that others will hold a negative view of them and will be unresponsive to their needs (Mikulincer and Shaver 2007). On the other hand, avoidant supervisees feel uncomfortable with proximity and support seeking, and they tend to deny or downplay their emotional needs or struggles in an attempt to deactivate the attachment system (Mikulincer and Shaver 2007a). Wrape and colleagues (2017) point out that supervisors should be particularly vigilant for signs of avoidant behaviours, such as withdrawal, lack of trust, and asking for little support or feedback, as these can hamper the progress of the research. Indeed, it has been suggested that a combination of avoidance in both leaders and followers can result in mutual disengagement (Keller and Cacioppe 2001). It would also be beneficial for supervisors to be 
aware not only of their supervisees' general attachment style, but also their supervision-specific attachment, which is formed in the context of previous supervisory experiences, considering that it has been found to be a stronger predictor of the quality of the supervisory working alliance (Wrape et al. 2017, Hinojosa et al. 2014). An attachment-based training for supervisors should also involve elements of self-awareness. For example, being aware of their own attachment style and of how it might differentially interact with their supervisees' attachment styles could help them regulate their emotional expression, behaviour, and feedback. It is worth noting that in most current conceptualisations (Gillath et al., 2019; Mikulincer, Shaver, and Rom 2011), attachment styles are not considered as fixed, non-amenable to change personality traits but as flexible schemas. Research from the field of personality and social psychology has indicated that attachment styles can change in a subtle or drastic ways depending on current context relational experiences. In fact, even brief experimental manipulations may move individuals, even though temporarily, closer to attachment security (Gillath et al. 2010). Finally, supervisors could be trained to provide a secure base and safe haven in the context of supervision. Preliminary evidence from one of our studies (Andriopoulou and Prowse, under review) exploring the role of secure-base supervision on research self-efficacy, curiosity and exploration, and satisfaction has revealed that supervisors' ability to provide a secure-base, by being available in times of need, non-interfering, and encouraging of exploration, predicted supervisees' levels of research selfefficacy and supervision satisfaction and this effect was stronger for anxiously attached supervisees. In addition, recent evidence coming from attachment-based parenting interventions have shown promise not only in enhancing children's sense of security (Huber, McMahon, and Sweller 2015a) and emotional functioning (Huber, McMahon, and Sweller 2015b), but also in 
reducing parental depression and boosting self-efficacy (Yaholkoski, Hurl, and Theule 2016).

Carefully designed training programmes for supervisors could yield similar outcomes.

Future research should examine the relevance of attachment theory in research degree supervision by adapting methodology and tools that have been particularly developed to assess attachment styles in the context of clinical supervision such as the "Experiences in Supervision Scale" (Gunn and Pistole 2012). A deeper understanding of the attachment processes and dynamics that are at play in doctoral supervisory relationships would inform supervisors' training programmes with an aim to enhance self-reflection and guide supervision practices. An interesting line of inquiry would also be to explore the role of the supervisor as a secure base for exploration and learning. For example, (Wu and Parker 2017) studied supervisor-employee dyads and found that the provision of secure-base support from leaders predicted role breadth self-efficacy and autonomous motivation which in turn led to higher levels of proactive work behaviour. Finally, further work is required to examine the potential impact of general and/or supervisor-specific attachment styles on supervisee's professional development, research degree satisfaction, and timely completion.

\section{Conclusion}

Research supervision is a complex form of pedagogy in the context of which supervisors are expected to possess and utilise a wide variety of skills including research and project management skills, teaching and knowledge transference skills, and interpersonal and relationship management skills. Nevertheless, the training they receive is mostly centred around university policies and procedures where the centrality and importance of the supervisory relationship is overlooked. The central proposition of this paper is that the supervisory relationship is first and foremost a human relationship governed by the rules of human 
communication and interaction. Attachment theory provides a potentially fruitful conceptual framework for studying and understanding the dynamics of the supervisory relationship. 


\section{References}

Ainsworth, Mary D Salter, Mary C Blehar, and Everett Waters. 1978. "Wall. s.(1978)." Patterns of attachment: A psychological study of the strange situation 18.

Anderson, Jean L. 1988. "The supervisory process in speech-language pathology and audiology." Ear and Hearing 9 (4):223.

Roach Alex, Christensen Bruce K., and Rieger, Elizabeth. 2019. "The essential ingredients of research supervision: A discrete-choice experiment." Journal of Educational Psychology. 111(7):1243-1260.

Bastalich, Wendy. 2017. "Content and context in knowledge production: a critical review of doctoral supervision literature." Studies in Higher Education 42 (7):1145-1157.

Bennett, Susanne, Jonathan Mohr, Karlynn BrintzenhofeSzoc, and Loretta Vitale Saks. 2008. "General and supervision-specific attachment styles: Relations to student perceptions of field supervisors." Journal of Social Work Education 44 (2):75-94.

Boberg, Alice L, and Sheryl A Monis-Khoo. 1992. "The Delphi method: A review of methodology and an application in the evaluation of a higher education program." The Canadian Journal of Program Evaluation 7 (1):27.

Bowden, John, and Pamela Green, (2019) Completion mindsets and contexts in doctoral education: Pursuing efficiency and quality with integrity. In: Playing the PhD Game with Integrity. Understanding Teaching-Learning Practice. Springer, Singapore

Bowlby, John. 1969. Attachment and Loss, Volume I Attachement: Penguin Books.

Bowlby, John. 1988. "A secure base New York." NY: Basic Books.

Collins, N. L. \& Read, S. J. 1994. "Cognitive representations of attachment: The structure and function of working models." In Advances in personal relationships, Vol. 5. Attachment processes in adulthood, edited by K. Bartholomew \& D. Perlman, 53-90. London, England: Jessica Kingsley Publishers.

Collins, N. L., and S. J. Read. 1994. "Cognitive representations of attachment: The structure and function of working models." In Advances in personal relationships, Vol. 5. Attachment processes in adulthood, edited by K. Bartholomew and D. Perlman, 53-90. London, England: Jessica Kingsley Publishers.

Collins, Nancy L. 1996. "Working models of attachment: Implications for explanation, emotion, and behavior." Journal of personality and social psychology 71 (4):810.

Davidovitz, Rivka, Mario Mikulincer, Phillip R Shaver, Ronit Izsak, and Micha Popper. 2007. "Leaders as attachment figures: Leaders' attachment orientations predict leadershiprelated mental representations and followers' performance and mental health." Journal of Personality and social Psychology 93 (4):632.

DeMarco, T. C., \& Newheiser, A. K. (2019). When groups do not cure: Group esteem moderates the social cure effect. European Journal of Social Psychology, 49(7), 1421-1438.

Deuchar, Ross. 2008. "Facilitator, director or critical friend?: Contradiction and congruence in doctoral supervision styles." Teaching in higher education 13 (4):489-500. 
Dickson, Joanne M, Nicholas J Moberly, Yehuda Marshall, and James Reilly. 2011. "Attachment style and its relationship to working alliance in the supervision of British clinical psychology trainees." Clinical psychology \& psychotherapy 18 (4):322-330.

Foster, Joel T, James W Lichtenberg, and Vicki Peyton. 2007. "The supervisory attachment relationship as a predictor of the professional development of the supervisee." Psychotherapy research 17 (3):343-350.

Foster, JT, AD Heinen, JW Lichtenberg, and AD Gomez. 2006. "Supervisor attachment as a predictor of developmental ratings of supervisees." American Journal of Psychological Research 2 (1):28-39.

Frazier, M Lance, Janaki Gooty, Laura M Little, and Debra L Nelson. 2015. "Employee attachment: Implications for supervisor trustworthiness and trust." Journal of Business and Psychology 30 (2):373-386.

Gatfield, Terry. 2005. "An investigation into PhD supervisory management styles: Development of a dynamic conceptual model and its managerial implications." Journal of Higher Education Policy and Management 27 (3):311-325.

Gillath, Omri, and Gery Karantzas. "Attachment security priming: A systematic review." Current opinion in psychology 25 (2019): 86-95.

Gillath, Omri, Amanda K Sesko, Phillip R Shaver, and David S Chun. 2010. "Attachment, authenticity, and honesty: dispositional and experimentally induced security can reduce self-and other-deception." Journal of personality and social psychology 98 (5):841.

Guerin, C., Kerr, H., \& Green, I. (2015). Supervision pedagogies: Narratives from the field. Teaching in Higher Education, 20(1), 107-118.

Grant, B.. 1999. "Walking on a rackety bridge: mapping supervision." HERDSA Annual International Conference.

Grant, B., 2003. Mapping the pleasures and risks of supervision. Discourse: studies in the cultural politics of education, 24(2), pp.175-190.

Green, Pam. 2005. Supervising postgraduate research: Contexts and processes, theories and practices, Supervising Postgraduate Research: Contexts and Processes, Theories and Practices. Melbourne: RMIT University Press.

Gruzdev, Ivan., Evgeniy Terentev and Zibeyda Dzhafarova. 2019. "Superhero or hands-off supervisor? An empirical categorization of PhD supervision styles and student satisfaction in Russian universities." Higher Education, pp.1-17.

Gunn, Joshua E, and M Carole Pistole. 2012. "Trainee supervisor attachment: Explaining the alliance and disclosure in supervision." Training and Education in Professional Psychology 6 (4):229.

Gurr, Geoff M. 2001. "Negotiating the" Rackety Bridge"—a dynamic model for aligning supervisory style with research student development." Higher Education Research \& Development 20 (1):81-92.

Halbert, Kelsey. 2015. "Students' perceptions of a 'quality'advisory relationship." Quality in Higher Education 21 (1):26-37. 
Hill, E Wayne. 1992. "Marital and family therapy supervision: A relational-attachment model." Contemporary family therapy 14 (2):115-125.

Hinojosa, Amanda S, Kelly Davis McCauley, Brandon Randolph-Seng, and William L Gardner. 2014. "Leader and follower attachment styles: Implications for authentic leader-follower relationships." The Leadership Quarterly 25 (3):595-610.

Huber, Anna, Catherine A McMahon, and Naomi Sweller. 2015a. "Efficacy of the 20-week circle of security intervention: Changes in caregiver reflective functioning, representations, and child attachment in an Australian clinical sample." Infant mental health journal 36 (6):556-574.

Huber, Anna, Catherine McMahon, and Naomi Sweller. 2015b. "Improved child behavioural and emotional functioning after Circle of Security 20-week intervention." Attachment \& human development 17 (6):547-569.

Hutchings, Maggie. 2017. "Improving doctoral support through group supervision: analysing face-to-face and technology-mediated strategies for nurturing and sustaining scholarship." Studies in Higher Education 42 (3):533-550.

Kafetsios, Konstantinos, Maria Athanasiadou, and Nafsika Dimou. 2014. "Leaders' and subordinates' attachment orientations, emotion regulation capabilities and affect at work: A multilevel analysis." The Leadership Quarterly 25 (3):512-527.

Kamler, Barbara, and Pat Thomson. 2014. Helping doctoral students write: Pedagogies for supervision. Routledge.

Keller, Tiffany, and Ron Cacioppe. 2001. "Leader-follower attachments: Understanding parental images at work." Leadership \& Organization Development Journal 22 (2):70-75.

L. Robertson, Jennifer, Angela M Dionisi, and Julian Barling. 2018. "Linking attachment theory to abusive supervision." Journal of Managerial Psychology 33 (2):214-228.

Lee, Anne. 2008. "How are doctoral students supervised? Concepts of doctoral research supervision." Studies in Higher Education 33 (3):267-281.

Lee, Anne. 2018. "How can we develop supervisors for the modern doctorate?" Studies in Higher Education 43 (5):878-890.

Lee, Anne, and Rowena Murray. 2015. "Supervising writing: Helping postgraduate students develop as researchers." Innovations in Education and Teaching International 52 (5):558-570.

Lindsay, Siân. 2015. "What works for doctoral students in completing their thesis?" Teaching in Higher Education 20 (2):183-196.

Mainhard, Tim, Roeland Van Der Rijst, Jan Van Tartwijk, and Theo Wubbels. 2009. "A model for the supervisor-doctoral student relationship." Higher education 58 (3):359-373.

Mayseless, Ofra, and Micha Popper. 2019. "Attachment and leadership: review and new insights." Current opinion in psychology 25:157-161.

McCallin, Antoinette, and Shoba Nayar. 2012. "Postgraduate research supervision: A critical review of current practice." Teaching in Higher Education 17 (1):63-74. 
McKibben, W Bradley, and Wesley B Webber. 2017. "Investigating the impact of supervisee attachment system activation on the supervisory relationship." The Clinical Supervisor 36 (2):324-339.

Mikulincer, Mario, and Phillip R Shaver. 2007a. Attachment in adulthood: Structure, dynamics, and change: Guilford Press.

Mikulincer, M., \& Shaver, P. R. (2007b). Attachment, group-related processes, and psychotherapy. International Journal of Group Psychotherapy, 57(2), 233-245.

Mikulincer, Mario, Phillip R Shaver, and Dana Pereg. 2003. "Attachment theory and affect regulation: The dynamics, development, and cognitive consequences of attachmentrelated strategies." Motivation and emotion 27 (2):77-102.

Mikulincer, Mario, Phillip R Shaver, and Eldad Rom. 2011. "The effects of implicit and explicit security priming on creative problem solving." Cognition and Emotion 25 (3):519-531.

Nelson, Mary Lee, Kristin L Barnes, Amelia L Evans, and Patrick J Triggiano. 2008. "Working with conflict in clinical supervision: Wise supervisors' perspectives." Journal of Counseling Psychology 55 (2):172.

Orellana, Martha L, Antònia Darder, Adolfina Pérez, and Jesús Salinas. 2016. "Improving doctoral success by matching $\mathrm{PhD}$ students with supervisors." International Journal of Doctoral Studies 11 (87-103).

Pistole, M Carole, and C Edward Watkins Jr. 1995. "Attachment theory, counseling process, and supervision." The Counseling Psychologist 23 (3):457-478.

Popper, Micha, Ofra Mayseless, and Omri Castelnovo. 2000. "Transformational leadership and attachment." The Leadership Quarterly 11 (2):267-289.

Renfro-Michel, Edina L, and Carl J Sheperis. 2009. "The relationship between counseling supervisee attachment orientation and perceived bond with supervisor." The Clinical Supervisor 28 (2):141-154.

Richards, David A, and Rick D Hackett. 2012. "Attachment and emotion regulation: Compensatory interactions and leader-member exchange." The Leadership Quarterly 23 (4):686-701.

Riggs, Shelley A, and Karen M Bretz. 2006. "Attachment processes in the supervisory relationship: An exploratory investigation." Professional Psychology: Research and Practice 37 (5):558.

Rogers, Jennifer L, Melissa Luke, Dennis D Gilbride, and Kristopher M Goodrich. 2019. "Supervisee Attachment, Cognitive Distortions, and Difficulty With Corrective Feedback." Counselor Education and Supervision 58 (1):18-32.

Rom, E., \& Mikulincer, M. (2003). Attachment theory and group processes: The association between attachment style and group-related representations, goals, memories, and functioning. Journal of Personality and Social Psychology, 84(6), 1220.

Sibley, Chris G, and Nickola C Overall. 2008. "Modeling the hierarchical structure of attachment representations: A test of domain differentiation." Personality and Individual Differences 44 (1):238-249. 
Smith, E. R., Murphy, J., \& Coats, S. (1999). Attachment to groups: Theory and management. Journal of Personality and Social Psychology, 77(1), 94.

Spronken-Smith, Rachel, Cameron, C. \& Quigg, R. 2018. Factors contributing to high PhD completion rates: a case study in a research-intensive university in New Zealand, Assessment \& Evaluation in Higher Education, 43:1, 94-109, DOI: 10.1080/02602938.2017.1298717

Watkins Jr, C Edward, and Shelley A Riggs. 2012. "Psychotherapy supervision and attachment theory: Review, reflections, and recommendations." The Clinical Supervisor 31 (2):256289.

White, Victoria E, and John Queener. 2003. "Supervisor and supervisee attachments and social provisions related to the supervisory working alliance." Counselor Education and Supervision 42 (3):203-218.

Wollast, Robin, Gentiane Boudrenghien, Nicolas Van der Linden, BenoÃŽt Galand, Nathalie Roland, Christelle Devos, MikaÃĜ̣l De Clercq, Olivier Klein, Assaad Azzi, and Mariane Frenay. 2018. "Who Are the Doctoral Students Who Drop Out? Factors Associated with the Rate of Doctoral Degree Completion in Universities." International Journal of Higher Education 7 (4): 143-156.

Wrape, Elizabeth R, Jennifer L Callahan, Troy Rieck, and C Edward Watkins Jr. 2017. "Attachment theory within clinical supervision: Application of the conceptual to the empirical." Psychoanalytic Psychotherapy 31 (1):37-54.

Wright, Toni, and Ray Cochrane. 2000. "Factors influencing successful submission of $\mathrm{PhD}$ theses." Studies in higher education 25 (2):181-195.

Wu, Chia-Huei, and Sharon K Parker. 2017. "The role of leader support in facilitating proactive work behavior: A perspective from attachment theory." Journal of Management 43 (4):1025-1049.

Wu, Chia-Huei, Sharon K Parker, and Jeroen PJ De Jong. 2014. "Feedback seeking from peers: A positive strategy for insecurely attached team-workers." Human relations 67 (4):441464.

Wubbels, Th, Mieke Brekelmans, Perry den Brok, and JWF Van Tartwijk. 2006. "An interpersonal perspective on classroom management in secondary classrooms in the Netherlands." In Handbook of classroom management: Research, practice, and contemporary issues, edited by C Evertson and C Weinstein, 1161-1191. Mahwah, NJ: Lawrence Erlbaum Associates.

Yaholkoski, Amber, Kylee Hurl, and Jennifer Theule. 2016. "Efficacy of the circle of security intervention: a meta-analysis." Journal of Infant, Child, and Adolescent Psychotherapy 15 (2):95-103.

Yip, Jeffrey, Kyle Ehrhardt, Hunter Black, and Dayna O Walker. 2018. "Attachment theory at work: A review and directions for future research." Journal of Organizational Behavior 39 (2):185-198. 
